\title{
Pengaruh Persepsi Konsumen terhadap Keputusan Pembelian pada Perum Bulog sub Divre Pematangsiantar
}

(Studi Kasus pada Konsumen Beras Bulog di Kecamatan Siantar Martoba)

\section{Mega Romauly Tampubolon}

Sekolah Tinggi Akuntansi Dan Manajemen Indonesia

tampubolonmega75@gmail.com

\section{Muhammad Yunus}

Sekolah Tinggi Akuntansi Dan Manajemen Indonesia

m.yunus4994@gmail.com

\section{Liana}

Sekolah Tinggi Akuntansi Dan Manajemen Indonesia liana.mnj@gmail.com

\begin{abstract}
The purpose of this study is: to determine the effect of consumer perceptions on purchasing decisions at Perum Bulog Sub Divre Pematangsiantar. This study uses a library research design and field research. This type of data uses qualitative and quantitative data. Data sources are primary data and secondary data. Data collection was carried out by means of questionnaires, interviews and documentation. Test the research instrument using the validity test and reliability test. The data analysis technique used is normality test, qualitative descriptive analysis and quantitative descriptive analysis. The results of this study can be concluded as follows: Consumer perceptions have a positive and significant effect on purchasing decisions either simultaneously or partially. There is a strong and positive relationship between consumer perceptions of purchasing decisions. The level of purchase decisions can be explained by consumer perceptions. Consumer perceptions have a positive and significant effect on purchasing decisions at Perum Blog Sub Divre Pematangsiantar
\end{abstract}

Keywords $\quad$ Consumer Perceptions, Purchasing Decisions

\section{PENDAHULUAN}

Perum Bulog Pematangsiantar merupakan perusahaan umum milik negara yang bergerak pada bidang logistik pangan. Ruang lingkup bisnis perusahaan meliputi usaha logistik/pergudangan, survey dan pemberantasan hama, penyedia karung plastik, usaha angkutan, perdagangan komoditi pangan dan usaha eceran. Sebagai perusahaan yang telah mengemban tugas publik dari pemerintah, Bulog tetap melakukan kegiatan menjaga harga dasar pembelian untuk gabah, stabilitasi harga khususnya harga pokok, menyalurkan beras orang miskin dan pengelolahan stok pangan. Tujuan Perum Bulog Pematangsiantar adalah memberikan pelayanan prima kepada pemangku kepentingan lainnya untuk memenuhi kebutuhan pangan pokok.

Keputusan pembelian oleh konsumen adalah keputusan yang melibatkan persepsi reputasi dan kredibilitas merek yang kemudian menjadi pedoman bagi konsumen untuk menggunakan suatu produk maupun jasa dari perusahaan. Keputusan pembelian merupakan tahap pada konsumen untuk membli 
produk yang dihasilkan [1]. Pembeli lebih suka dengan produk-produk atau kualitas yang sudah terkena. Adapun keputusan pembelian menggunakan lima dimensi antara lain pengenalan kebutuhan, pencarian informasi, evaluasi alternatif, keputusan pembelian konsumen dan perilaku pasca pembelian.

Fenomena keputusan pembelian konsumen pada Bulog belum optimal. Hal ini dapat dilihat pada dimensi pencarianinformasi, dimana konsumen harusmendatangi kantor Bulog Pematangsiantar untuk mencari informasi mengenai beras yang dijual. Dapat dilihat juga padadimensi evaluasi alternatif, dimana konsumen membandingkan beras di Bulog dengan beras yang dijual oleh pihak lain.

Salah satu yang pendorong keputusan pembelian konsumen adalah persepsi. Persepsi merupakan komponen penting dalam menentukan keputusan pembelian konsumen. Hal ini juga sejalan dengan yang dilakukan oleh Syahputro, dkk. (2015) bahwa persepsi konsumen berpengaruh positif terhadap keputusan pembelian. Adapun dimensi pada persepsi konsumen terdiri dari 3 (tiga) yaitu seleksi, organisasi, dan pretensi.

Persepsi merupakan kepercayaan yang diperoleh oleh konsumen dalam suatu objek yang diperoleh dari informasi yang didapatkannya [2]. Persepsi konusmen pada suatu produk akan mempengaruhi keputusan pembelian konsumen dalam membeli produk tersebut [3].

Fenomena persepsi konsumen Perum Bulog Sub Divre Pematangsiantar yang belum optimal terdapat pada dimensi seleksi, ketika informasi yang didapatkan konsumen sangat minim karena tidak adanya iklan dari usaha sehingga konsumen kurang mengetahui penawaran-penawaran apa saja yang ada pada Perum Bulog Sub Divre Pematangsiantar. Pada organisasi persepsi, Bulog kurang memberikan informasi ke masyarakat, sehingga konsumen masih memiliki pengalaman buruk dimasa lalu saat berbelanja beras di Bulog Pematangsiantar

Dari uraian tersebut, terdapat adanya masalah-masalah antara harapan dan kenyataan. Rumusan masalah dalam penelitian ini adalah bagaimanapengaruh persepsi konsumen terhadap keputusan pembelian pada Perum Bulog Sub Divre Pematangsiantar. Maka tujuan penelitian ini adalah untuk mengetahui pengaruh persepsi konsumen terhadap keputusan pembelian pada Perum Bulog Sub Divre Pematangsiantar.

\section{LANDASAN TEORI}

\section{Manajemen Pemasaran}

Manajemen adalah suatu proses merencanakan, mengorganisasikan, sebuah manfaat atau kepemilikan atas produk maupun jasa yang diinginkan[4]. Salah satu kegiatan pokok yang dilakukan perusahaan adalah pemasaran [5]. Manajemen merupakan suatu proses khas yang terdiri atas tindakantindakan perencanaan, pengorganisasian, penggerakan dan pengendalian untuk menentukan serta mencapai tujuan melalui pemanfaatan sumber daya manusia dan sumber daya lainnya[6]. Aktivitasaktivitas pengorganisasian dan pengawasan terhadap pekerjaan orang lain sehingga pekerjaan tersebut diselesaikan secara efektif dan efisien.

\section{Persepsi Konsumen}

Persepsi melibatkan manfaat fungsional suatu produk dimata konsumen [7]. Persepsi konsumen adalah suatu proses yang timbul akibat adanya sensasi. Sensasi adalah aktivitas merasakan atau penyebab keadaan emosi yang menggembirakan[8]. Persepsi konsumen merupakan proses kita memilih, mengatur, dan menerjemahkan, masukan informasi untuk menciptakan gambaran dunia yang berarti [9]. Sedangkan Persepsi merupakan suatu proses yang timbul akibat adanya sensasi, di mana sensasi adalah bagaimana aktivitas merasakan atau penyebab keadaan emosi yang menggembirakan.

\section{Keputusan Pembelian}

Proses keputusan pembelian merupakan proses penting yang dipengaruhi pemasar melalui strategi yang dimiliki perusahaan [1]. Keputusan pembelian yaitu suatu keputusan pelanggan yang 
dipengaruhi oleh ekonomi keuangan, teknologi, politik, budaya, produk, harga, lokasi, promosi sehingga membentuk suatu sikap untuk mengolah segala informasi dan mengambil kesimpulan berupa respons produk mana saja yang akan dibeli[10].

Keputusan pembelian pelanggan adalah proses pengambilan keputusan yang sangat dipengaruhi oleh perilaku pelanggan[10]. Proses tersebut sebenarnya merupakan proses pemecahan masalah dalam rangka memenuhi keinginan atau kebutuhan pelanggan.Keputusan pembelian adalah proses pengintegrasian yang mengkombinasikan pengetahuan untuk mengevaluasi dua perilaku alternatif atau lebih dan memilih salah satu diantaranya.

\section{METODE PENELITIAN}

Pendekatan asosiatif digunakan dalam penelitian ini. Desain penelitian yang digunakan penulis adalah Penelitian lapangan (Field Research).Dalam observasi tersebut memakai suatu cara observasi daftar pustaka serta penelitian secara langsung[11]. Waktu penelitian ini dilaksanakan kurang lebih selama Sembilan bulan.

Adapun yang menjadi tempat penelitian ini Perum Bulog Sub Divre Pematangsiantar, Jalan Asahan No. 29 Siantar Estate, Kecamatan Siantar Simalungun, Sumatera Utara, Indonesia. Yang dikatakan sebagai objek pada penelitian tersebut yaitu konsumen beras Bulog Pematangsiantar yang berjumlah 50 di Kecamatan Siantar Martoba.

Jenis data yang dipakai yaitu data kualitatif dan data kuantitatif.Sumber data yang digunakan adalah data primer dan data sekunder.Pengumpulan data dilakukan dengan menggunakan kuesioner, wawancara, dan dokumentasi.Teknik analisis yang digunakan adalah uji normalitas, analisis deskriptif kualitatif dan analisis deskriptif kuantitatif.

\section{HASIL DAN PEMBAHASAN}

HASIL

\section{Uji Normalitas}

Uji normalitas dilaksanakan agar melihat apakah sebuah perolehan data dari populasi yang berdistribusi normal.Dalam penelitian ini uji normalitas menggunakan uji KolmogorovSmirnov.Kolgomorov-Smirnov Test diperoleh angka probabilitas atau Asym.Sig (2-tailed). Berikut hasil uji normalitas menggunakan SPSS versi 21:

Tabel 1. Hasil Uji Normalitas

\begin{tabular}{|c|c|c|c|c|}
\hline \multicolumn{5}{|c|}{ One-Sample Kolmogorov-Smirnov Test } \\
\hline & & $\mathbf{x}$ & $\mathbf{y}$ & Total \\
\hline \multicolumn{2}{|l|}{$\mathrm{N}$} & 50 & 50 & 50 \\
\hline \multirow{2}{*}{ Normal Parameters $s^{a, b}$} & Mean & 31.06 & 54.32 & 186.12 \\
\hline & Std. Deviation & 5.073 & 8.123 & 27.165 \\
\hline \multirow{3}{*}{ Most Extreme Differences } & Absolute & .129 & .078 & .082 \\
\hline & Positive & .086 & .078 & .052 \\
\hline & Negative & -.129 & -.075 & -.082 \\
\hline \multicolumn{2}{|c|}{ Kolmogorov-Smirnov $Z$} & .912 & .552 & .582 \\
\hline \multicolumn{2}{|c|}{ Asymp. Sig. (2-tailed) } & .377 & .921 & .887 \\
\hline \multicolumn{5}{|c|}{ a. Test distribution is Normal. } \\
\hline \multicolumn{5}{|c|}{ b. Calculated from data. } \\
\hline
\end{tabular}

Sumber: hasil pengolahan kuesioner menggunakan SPSS versi 21 (2020) 
Sesuai tabel 1 nilai Asymp. Sig (2-tiled) total X(persepsi konsumen) sejumlah 0,377, dan total Y (keputusan pembelian) sejumlah 0,921 serta total keseluruhan 0,887 nilai Asymp. Sig (2-tailed) > 0,05. Artinya data masing-masing normal.

\section{Analisis Regresi Linear Sederhana}

Analisis regresi linier sederhana dalam penelitian ini digunakan untuk mengetahui pengaruh antara persepsi konsumen $\left(\mathrm{X}_{1}\right)$ terhadap keputusan pembelian pelanggan pada Perum Bulog Sub Divre Pematangsiantar.Maka perhitungan menggunakan SPSS versi 21 dengan notasi sebagai berikut:

Tabel 2. Hasil Regresi Linear Sederhana Persepsi Konsumen Terhadap Keputusan Pembelian

\begin{tabular}{|c|c|c|c|c|}
\hline \multicolumn{5}{|c|}{ Coefficients $^{a}$} \\
\hline \multirow{2}{*}{\multicolumn{2}{|c|}{ Model }} & \multicolumn{2}{|c|}{$\begin{array}{c}\text { Unstandardized } \\
\text { Coefficients }\end{array}$} & $\begin{array}{c}\text { Standardized } \\
\text { Coefficients }\end{array}$ \\
\hline & & $\boldsymbol{B}$ & Std. Error & Beta \\
\hline \multirow{2}{*}{1} & $($ Constant $)$ & $\begin{array}{r}18.33 \\
0\end{array}$ & 5.049 & \\
\hline & $\mathrm{x} 1$ & 1.152 & .160 & .720 \\
\hline
\end{tabular}

Sumber: hasil pengolahan kuesioner dengan SPSS versi 21 (2020)

Hasil pengolahan data pada tabel 4 di atas diperoleh persamaan $\hat{Y}=18,330+5,049 \mathrm{X}_{1}$, artinya apabila $\mathrm{X}_{1}$ naik satu satuan, maka $\mathrm{Y}$ naik sebesar 5,049 satuan. Sehingga dapat disimpulkan bahwa terdapat pengaruh positif antara persepsi konsumen terhadap keputusan pembelian pada Perum Bulog Sub Divre Pematangsiantar

\section{Korelasi dan Koefisien Determinasi}

Perhitungan korelasi berupa derajat atau kedalaman hubungan fungsional yang menjelaskan hubungan antara perubah, dinyatakan dengan yang dinamakan korelasi yang sering disimbolkan dengan $\mathrm{r}$, nilai $\mathrm{r}$ dapatdihitung menggunakan SPSS versi 21 . Hasil korelasi dan koefisien determinasi dapat dilihat pada tabel berikut ini:

Tabel 3. Hasil Korelasi dan Koefisien Determinasi

\begin{tabular}{|l|c|r|r|r|}
\hline \multicolumn{5}{|c|}{ Model Summary } \\
\hline Model & $R$ & $R$ Square & Adjusted $R$ Square & Std. Error of the Estimate \\
\hline 1 & $.744^{\mathrm{a}}$ & .554 & .535 & 5.540 \\
\hline a. Predictors: (Constant), $\mathrm{x} 2, \mathrm{x} 1$ \\
\hline \multicolumn{2}{|l|}{ b. Dependent Variable: $\mathrm{y}$} \\
\hline
\end{tabular}

Sumber: hasil pengolahan kuesioner menggunakan SPSS versi 21 (2020)

Dari hasil korelasi di atas diperoleh nilai korelasi(r) $=0,744$ yang artinya terdapat hubungan yang kuat dan positif antara persepsi konsumen dengan keputusan pembelian pada Bulog Sub Divre Kota Pematangsiantar sesuai dengan kriteria korelasi pada tabel 3.4.

Kemudian diperoleh nilai koefisien determinasi $(\mathrm{R})=0,554$, artinya baik tidaknya keputusan pembelian (Y) pada Perum Bulog Sub Divre Pematangsiantar sebesar 55,4\% dapat dijelaskan oleh persepsi konsumen (X) sedangkan sisanya sebesar44,6\% dipengaruhi oleh faktor lain seperti kualitas pelayanan, harga, promosi dan variabel lainnya yang tidak diteliti dalam penelitian ini. 


\section{Pengujian Hipotesis}

Pengujian ini dilakukan untuk menentukan diterimanya atau ditolaknya hipotesis, pengujian hipotesis dilakukan untuk mengetahui apakah variabel persepsi konsumen dan kualitas produk yang diuji berpengaruh terhadap keputusan pembelian. Jika $t_{\text {hitung }}>t_{\text {tabel }}$ atau signifikansi $\leq 0,05$ maka $\mathrm{H}_{0}$ ditolak. Untuk menguji kebenarannya maka dilakukan pengujian hipotesis dengan menggunakan aplikasi SPSS versi 21 .

Tabel 4. Hasil Uji thitung Persepsi Konsumen terhadap Keputusan Pembelian

\begin{tabular}{|c|c|c|}
\hline Model & $\mathbf{t}$ & Sig. \\
\hline (Constant) & 3.669 & .001 \\
\hline $\mathbf{X}$ & 7.182 & .000 \\
\hline
\end{tabular}

a. Dependent Variable: $y$

Sumber: hasil pengolahan kuesioner menggunakan SPSS versi 21 (2020).

Hasil diperoleh nilai $t_{\text {hitung }}$ pada variabel persepsi konsumen $(X)$ sebesar 7.182> $t_{\text {tabel }}$ dengan $d k=n-2$ $(50-2=48)$ sebesar 2,01063 atau taraf signifikan $0,000<\alpha 0,05$, maka $\mathrm{H}_{0}$ ditolak, artinya persepsi konsumen berpengaruh positif dan signifikan terhadap keputusan pembelian konsumen pada Perum Bulog Sub Divre Pematangsiantar. Hal ini didukung oleh penelitian[5], [12],yang menyatakan bahwa persepsi konsumen berpengaruh positif dan signifikan terhadap keputusan pembelian.

\section{PEMBAHASAN}

Berdasarkan hasil kuesioner dan penelitian dapat disimpulkan bahwa persepsi konsumen beras Perum Bulog Sub Divre Pematangsiantar.Selain upaya memperbaiki persepsi konsumen yang sudah dijelaskan diatas, Perum Bulog Sub Divre Pematangsiantar juga dapat mendorong persepsi konsumen dengan memperhatikan faktor-faktor yang mempengaruhi persepsi konsumen seperti yang dikemukakan oleh yaitu objek yang dipersepsikan, alat indera (syaraf dan susunan saraf), dan perhatian[13].

Selain upaya meningkatkan keputusan pembelian konsumen yang sudah dijelaskan diatas Perum Bulog Sub Divre Pematangsiantar juga dapat menciptakan keputusan pembelian konsumen dengan memperhatikan pengaruh lainnya seperti ekonomi keuangan, teknologi, politik, budaya, produk, harga, lokasi, promosi sehingga membentuk suatu sikap untuk mengolah segala informasi dan mengambil kesimpulan berupa respon produk mana saja yang akan dibeli, hal tersebut dikemukakan oleh Alma (2013).

\section{KESIMPULAN DAN SARAN Kesimpulan}

Hasil analisis deskriptif kualitatif tentang persepsi konsumen diperoleh hasil dengan kriteria jawaban baik. Nilai rata-rata tertinggi terdapat pada dimensi interpretasi untuk indikator lokasi. Sedangkan nilai rata-rata terendah dengan kriteria jawaban cukup baik terdapat pada dimensi seleksi persepsi dengan indikator informasi yang diterima. Hasil analisis regresi linear sederhana menunjukkan bahwa terdapat pengaruh positif antara persepsi konsumen terhadap keputusan pembelian pada Perum Bulog Sub Divre Pematangsiantar dan terdapat pengaruh positif antara kualitas produk beras terhadap keputusan pembelian pada Perum Bulog Sub Divre Pematangsiantar. Hasil analisis korelasi diperoleh hubungan yang kuat dan positif antara persepsi konsumen dengan keputusan pembelian pada Perum Bulog Sub Divre Pematangsiantar. Kemudian baik tidaknya keputusan pembelian pada Perum Bulog Sub Divre Pematangsiantar dapat dijelaskan oleh persepsi konsumen dan kualitas produk. Hasil hipotesis pengujian uji parsial (Uji t) menunjukkan bahwa persepsi konsumen berpengaruh positif dan signifikan terhadap keputusan pembelian pelanggan pada Perum Bulog Sub Divre Pematangsiantar secara parsial. 


\section{Saran}

Berdasarkan kesimpulan dan hasil evaluasi penelitian yang telah dilakukan, maka penulis memberikan beberapa saranUntuk meningkatkan persepsi konsumen pada beras Perum Bulog Sub Divre Pematangsiantar sebaiknya Bulog memberikan penjelasan yang lebih rinci dan akurat mengenai beras yang dijual. Untuk meningkatkan keputusan pembelian konsumen, Perum Bulog Sub Divre Pematangsiantar sebaiknya dapat mengetahui jenis beras yang dibutuhkan oleh konsumen dan memenuhi kebutuhan tersebut.

\section{DAFTAR PUSTAKA}

[1] P. Suryana and E. S. Dasuki, "Analisis Faktor yang Mempengaruhi Keputusan Pembelian dan Implikasinya pada Minat Beli Ulang," Trikonomika, vol. 12, no. 2, p. 190, 2013, doi: 10.23969/trikonomika.v12i2.479.

[2] C. Mutimukwe, E. Kolkowska, and Å. Grönlund, "Information privacy in e-service: Effect of organizational privacy assurances on individual privacy concerns, perceptions, trust and selfdisclosure behavior," Gov. Inf. Q., vol. 37, no. 1, p. 101413, 2020, doi: 10.1016/j.giq.2019.101413.

[3] K. J. Adinata and N. N. K. Yasa, "Pengaruh Kepercayaan, Persepsi Harga, Dan Sikap Terhadap Niat Beli Kembali Di Situs Lazada," E-Jurnal Manaj. Univ. Udayana, vol. 7, no. 8, p. 4153, 2018, doi: 10.24843/ejmunud.2018.v07.i08.p05.

[4] H. T. Handoko, Manajemen Sumber Daya Manusia. Yogyakarta: BPFE, 2012.

[5] D. E. Putri, O. S. Sinaga, S. S. Agustina, H. P. Silitonga, and A. Sudirman, "Minat Kunjungan Ulang Pasien yang Ditinjau dari Aspek Persepsi dan Kepercayaan pada Klinik Vita Medistra Pematangsiantar," vol. 8, pp. 41-46, 2020.

[6] G. Terry and L. W Rue, Dasar Dasar Manajemen, Kesebelas. Jakarta: Bumi Aksara, 2010.

[7] A. P. Ariasa, Muhammad, N. Rachma, "Pengaruh Atribut Produk, Persepsi Nilai, Pengalaman Konsumen terhadap Minat Beli Ulang Yang di mediasi Oleh Kepuasan Konsumen (Pada Pengguna Smartphone Xiaomi di Kelurahan Dinoyo, Malang),” vol. 8, no. 7, pp. 16-30, 2019.

[8] Sangadji and Sopiah, Consumer Behavior: Perilaku Konsumen dan Strategi pemasaran, II. Jakarta: Erlangga, 2013.

[9] Philip Kotler and G. Amstrong, Prinsip-Prinsip Pemasaran, 12, Jilid ed. Jakarta: Erlangga, 2012.

[10] B. Alma, Manajemen Pemasaran dan Pemasaran Jasa. Bandung: Alfabeta, 2013.

[11] Sugiyono, Metode Penelitian Kuantitatif Kualitatif dan R\&D. Bandung: Alfabeta, 2017.

[12] B. S. Nuraeni, "Analisis Faktor-Faktor Yang Mempengaruhi Minat Kunjung Ulang Wisatawan Museum Ranggawarsita Semarang,” J. Bisnis Strateg., vol. 23, no. 1, pp. 1-20, 2014.

[13] P. Donni J, Perilaku Konsumen Dalam Persaingan Bisnis Kontemporer. Bandung: Alfabeta, 2017. 